\title{
DETERMINING THE DIMENSIONS OF THE INNOVATION ABILITY IN LOGISTICS SECTOR BY USING PLITHOGENIC-CRITIC METHOD: AN APPLICATION IN SAKARYA PROVINCE
}

\author{
KORUCUK Selcuk ${ }^{1}$, DEMIR Ezgi ${ }^{2}$, KARAMASA Caglar $^{3}$, STEVIĆ Željko ${ }^{4}$ \\ ${ }^{1}$ Bulancak Kadir Karabaş Applied Sciences School, Giresun University, Department of International Logistics and \\ Transportation (TURKEY) \\ ${ }^{2}$ Faculty of Economics and Administrative Sciences, Piri Reis University, Department of Management Information Systems \\ (TURKEY) \\ ${ }^{3}$ Faculty of Management, Anadolu University, Department of Business Administration (TURKEY) \\ ${ }^{4}$ Faculty of Transport and Traffic Engineering, University of East Sarajevo (BOSNIA AND HERZEGOVINIA) \\ Emails: selcuk.korucuk@giresun.edu.tr,edemir@pirireis.edu.tr, ckaramasa@anadolu.edu.tr, zeljkostevic88@yahoo.com
}

\begin{abstract}
Today's changing and developing level of competition and power, continuous learning, knowledge and technology management, transformation in the production process, marketoriented-based innovation and knowledge as communication applications, companies are routed to make more resources and research about the ability of innovation. The innovation factor has enabled new processes, products, ideas to adapt successfully for the production and market structure, and correspondingly implementation of them. In this point of view, innovation ability is the integration of new information resulting in product and process innovation by activating the power that a company provides to its employees. This ability has referred to the information between internal knowledge and external market demands.

Accordingly, the factors affecting the innovation capability dimensions have a vital importance for companies. The fact that there exist limited number of studies on the weighting of the factors affecting the dimensions of innovation ability in the comprehensive literature review, is another factor increasing the importance of the subject. In this study, the innovation ability dimensions have been weighted in corporate logistics companies in Sakarya. Plithogenic set based CRITIC method, which is one of the multi criteria decision making techniques, has been used. The most important factor in the study was determined to be ability of accessing information resources.
\end{abstract}

Keywords: innovation; innovation ability; dimesions of innovation ability; Plithogenic Sets; CRITIC

JEL: C02, C44, O32

UDC: 005.591.6.005.912:658.86/.87(560)

COBISS.SR-ID: 18197257

\section{Introduction}

Innovation factor, which is the adaptation and integration of ideas or behaviors to the company, is a concept that have a direct relationship with the dynamic structures of companies, competitiveness, R\&D activities, skills to develop their basic skills and their level of use of technology. Therefore, innovation may be considered as a strategical requirement for companies to survive in the global, competitive environment and market conditions to sustain their existence. 
Fundamentally innovation, generally based on research and development, is considered to be associated with new product development/production [1]. Especially the new economic structure that has emerged as a result of globalization has increased the severity of the existing competition in the sectors in which businesses operate. In this economic structure, enterprises have to increase their competitiveness in order to survive. To achieve this, businesses have started to act in an innovative way to increase their competitiveness, reduce costs and/or to make a difference [2].

Innovation capabilities are extremely important for businesses to maintain their competitive structure against their competitors. In particular, small and medium-sized enterprises play a key role in enabling them to achieve their goals, due to their limited ability to move and respond flexibly [3]. In this context, the innovation capability examined in the study is generally considered as one of the most important dynamics that guide companies in order to get the innovation ability of a company and its advanced competitiveness in national and international markets [4].

Innovation capability is often synchronized with companies' official R\&D activities and innovation-output related new products. This linear innovation model has led to the emphasis on technological and scientific knowledge in firms and to consider formal R\&D studies as an indicator of firms' technological progress. Additionally, three variables are included in the analysis of innovation capacity, being the capabilities, internal resources, and external inputs over the network [5].

In this context, the sources in the literature show the dimensions of innovation capability that is vital for companies. They expressed as learning ability, R\&D ability, marketing ability, production ability, access to information resources, ability to use resources for the benefit of the company, creative thinking ability, organizational ability and strategic ability and [3]. The importance of creating innovation capability in all of the above-mentioned components plays an active role in ensuring that all the activities of the companies are performed smoothly, providing cost advantage and power of competitiveness. Creating the dimensions of innovation capability is a multi-criteria decision-making problem in which firms, planning, process efficiency and quantitative-qualitative elements are handled together on an operational and strategic level.

The purpose of the study in this context is to evaluate the dimensions of innovation ability in corporate logistics companies in the province of Sakarya. "CRITIC" has been used as one of the multi-criteria decision-making methods. In the following part of the study, the importance of innovation capability and comprehensive literature review for creating dimensions of innovation capability have included. In the third section, information about Plithogenic sets and Neutrosophic sets have been presented, and the application section of the study has been given in the following stage. In the last section, suggestions have been made regarding the results and future studies.

\section{Literature Review}

This section may be divided by subheadings. It should provide a concise and precise description of the experimental results, their interpretation as well as the experimental conclusions that can be drawn. Innovation ability has been used in various fields in the literature. In this context, the purpose and dimensions of the innovation capability are given in the Table 1. 
Table 1. Literature Review Related with Innovation Capability

\begin{tabular}{|c|c|c|}
\hline Authors & Dimensions & Aim of the Study \\
\hline $\begin{array}{l}\text { Moussaa \& El } \\
\text { Arbi [6] }\end{array}$ & $\begin{array}{l}\text {-Employees' } \\
\text { innovation capability } \\
\text {-Human Research } \\
\text { Information System } \\
\text { Usage (frequency of } \\
\text { use) }\end{array}$ & $\begin{array}{l}\text { This research focuses on the study of the impact of the HRIS' use in } \\
\text { human resources department (HR) on individual innovation capability. }\end{array}$ \\
\hline $\begin{array}{l}\text { Sheng } \\
\text { Margaret [21] }\end{array}$ & $\begin{array}{l}\text {-Number of } \\
\text { Employees } \\
\text {-Firm Age } \\
\text {-Number of } \\
\text { Subsidiaries } \\
\text {-Industry } \\
\text {-Joint Venture Entry } \\
\text { Mode } \\
\text {-Merger and } \\
\text { Acquisition Entry } \\
\text { Mode } \\
\text {-Strategic Alliance } \\
\text { Entry Mode } \\
\text {-Absorptive Capacity }\end{array}$ & $\begin{array}{l}\text { The hypotheses are tested on a data set consisting of survey data } \\
\text { collected from } 220 \text { senior managers or executives at the headquarters } \\
\text { of Taiwan-based MNCs. Interestingly, structural social capital between } \\
\text { headquarters and subsidiaries strengthens the negative association } \\
\text { between subsidiaries' cross-border knowledge tacitness shared and } \\
\text { explorative innovation capability; relational social capital attenuates } \\
\text { the negative association between subsidiaries' crossborder knowledge } \\
\text { tacitness shared and both explorative and exploitative innovation } \\
\text { capability. }\end{array}$ \\
\hline $\begin{array}{l}\text { Hansen et al., } \\
\text { [7] }\end{array}$ & $\begin{array}{l}\text {-Internal R\&D effort } \\
\text {-Hiring of skilled } \\
\text { managers and } \\
\text { workers } \\
\text { - Learning through } \\
\text { firms' acquisitions, } \\
\text { joint ventures and } \\
\text { licensing } \\
\text {-Learning within } \\
\text { firms at the local } \\
\text { (cluster or regional) } \\
\text { level } \\
\text { - Learning from } \\
\text { suppliers, } \\
\text { universities, service } \\
\text { providers } \\
\text {-Imitation from } \\
\text { competitors }\end{array}$ & $\begin{array}{l}\text { To examine the innovation capability development trajectory of a local } \\
\text { Indian subsidiary of a Danish first-tier supplier of wind turbine blades } \\
\text { by adopting an analytical framework based on the literature on } \\
\text { innovation capability building in latecomer firms, which is combined } \\
\text { with insights from the literature on Multi Nominal Companies } \\
\text { subsidiary capability evolution. }\end{array}$ \\
\hline $\begin{array}{l}\text { Alexe } \& \\
\text { Alexe }[8]\end{array}$ & $\begin{array}{l}\text {-Conditions } \\
\text {-Resources } \\
\text {-Processes } \\
\text {-Results } \\
\end{array}$ & $\begin{array}{l}\text { To determine the importance given to the dimensions of the innovation } \\
\text { in machine building industry contribute to the possibility of achieving } \\
\text { the analyzes of benchmarking on the innovation management among } \\
\text { various companies in other industries, in this case, the IT\&C industry. }\end{array}$ \\
\hline $\begin{array}{l}\text { Khedhaouria } \\
\& \text { Thurik [9] }\end{array}$ & $\begin{array}{l}\text {-Human capital and } \\
\text { research } \\
\text {-Infrastructure } \\
\text {-Institutions } \\
\text {-Market conditions } \\
\text {-Business conditions }\end{array}$ & $\begin{array}{l}\text { Building upon the national innovation system perspective and using a } \\
\text { fuzzy set qualitative comparative analysis approach (fsQCA), by } \\
\text { proposing an integrating framework to determine the conditions that } \\
\text { lead to high levels of national innovation capability outcomes. }\end{array}$ \\
\hline $\begin{array}{l}\text { Nada \& } \\
\text { Zulfiqar [10] }\end{array}$ & $\begin{array}{l}\text {-Strategic Capability } \\
\text {-Managerial } \\
\text { Capability } \\
\text {-Operational } \\
\text { Capability } \\
\text {-Adaptive Capability }\end{array}$ & $\begin{array}{l}\text { To explore and to find the relationship of service value creation } \\
\text { capability with service innovation capability and to assess the service } \\
\text { innovation by using a proposed model for service value creation } \\
\text { capability. The model in study is empirically validated in Danish and } \\
\text { Turkish SMEs to identify the correlation between the service value } \\
\text { creation and service innovation through an integrated service value } \\
\text { creation capability model analysis. }\end{array}$ \\
\hline
\end{tabular}




\section{Methodology}

\section{Plithogenic sets}

As a generalization of neutrosophic set, plithogenic sets consider the decision makers' views more accurate and consistent by taking truth, indeterminacy and falsity membership functions into the account. Plithogenic sets consist of elements which are characterized in terms of attribute values. The accuracy of results can be increased via using contradiction degree. Plithogenic set $(P S, B, S, a d, c d)$ consist elements described by attributes $B=$ $\left\{b_{1}, b_{2}, \ldots, b_{m}\right\}, m>1$, having the values $S=\left\{s_{1}, s_{2}, \ldots, s_{n}\right\}$, for $n>1$ [29]. Contradiction and appurtenance degrees constitute the plithogenic sets. Contradiction degree function $c d(s, D)$ is useful to compare the values of attribute and dominant values. Appurtenance degree function for the element $\mathrm{x}$ in terms of criteria can be written as $a d(x, s)$ [11], [12].

Consider $\mathrm{B}$ as a set consist of unidimensional attributes $B=\left\{b_{1}, b_{2}, \ldots, b_{m}\right\}, m>1$, and $b \in B$ as an attribute with value spectrum set $\mathrm{L}$ that can be described as finite discrete, infinitely countable or infinitely uncountable set with value range for attributes according to the judgments of decision makers $S=\left\{s_{1}, s_{2}, \ldots, s_{n}\right\}$, for $n>1$. Dominant value for attributes is determined by decision makers in terms of contradiction degree [12].

Contradiction degree function $c d\left(s_{1}, s_{2}\right)$ for attribute value can be written as $c d: S x S \rightarrow$ $[0,1]$. The type of contradiction degree function for attribute value can be defined as fuzzy, intuitionistic or neutrosophic too [12].

Appurtenance degree $\operatorname{ad}(x, s)$ for attribute value $\mathrm{s}$ is $\forall x \in P S$, ad: $P S x S \rightarrow P\left([0,1]^{t}\right)$, $\operatorname{ad}(x, s)$ is subset of $[0,1]^{t}$, and $P\left([0,1]^{t}\right)$ is power set of $[0,1]^{t}$ with respect to fuzzy, intuitionistic and neutrosophic appurtenance degrees for $\mathrm{t}=1,2,3$ [13].

\section{Neutrosophic Sets}

Neutrosophic Sets proposed by Smarandache [14] having with degree of truth, indeterminacy and falsity membership functions in which all of them are totally independent.

Let $\mathrm{U}$ be a universe of discourse and $x \in U$. The neutrosophic set $\mathrm{E}$ can be written with a truth membership function $T_{E}(x)$, an indeterminacy membership function $I_{E}(x)$ and a falsity membership function $F_{E}(x)$, and is shown as $E=\left\{\left\langle x: T_{E}(x), I_{E}(x), F_{E}(x)\right\rangle, x \in U\right\}$. Also the functions of $T_{E}(x), I_{E}(x)$ and $F_{E}(x)$ are real standard or real nonstandard subsets of ] $0^{-}, 1^{+}[$, and can be stated as $T, I, F: U \rightarrow] 0^{-}, 1^{+}[$. There is not any restriction on the sum of the functions of $T_{E}(x), I_{E}(x)$ and $F_{E}(x)$, so $0^{-} \leq \operatorname{supT}_{E}(x)+\sup _{E}(x)+\sup _{E}(x) \leq 3^{+}$.

Let a single valued neutrosophic triangular number $\tilde{b}=\left\langle\left(b_{1}, b_{2}, b_{3}\right) ; \alpha_{\tilde{b}}, \theta_{\tilde{b}}, \beta_{\tilde{b}}\right\rangle$ is a special neutrosophic set on R. Additionally $\alpha_{\tilde{b}}, \theta_{\tilde{b}}, \beta_{\tilde{b}} \in[0,1]$ and $b_{1}, b_{2}, b_{3} \in R$ where $b_{1} \leq$ $b_{2} \leq b_{3}$. Truth, indeterminacy and falsity membership functions of this number can be computed as below [15], [16], [17], [18]:

$$
\begin{gathered}
\mathrm{T}_{\tilde{b}}(x)=\left\{\begin{array}{cc}
\alpha_{\tilde{b}}\left(\frac{x-b_{1}}{b_{2}-b_{1}}\right) & \left(b_{1} \leq x \leq b_{2}\right) \\
\alpha_{\tilde{b}} & \left(\mathrm{x}=b_{2}\right) \\
\alpha_{\tilde{b}}\left(\frac{b_{3}-x}{b_{3}-b_{2}}\right) & \left(b_{2}<x \leq b_{3}\right) \\
0 & \text { otherwise }
\end{array}\right. \\
\mathrm{I}_{\tilde{b}}(x)=\left\{\begin{array}{cc}
\left(\frac{b_{2}-\mathrm{x}+\theta_{\tilde{b}}\left(\mathrm{x}-b_{1}\right)}{b_{2}-b_{1}}\right) & \left(b_{1} \leq x \leq b_{2}\right) \\
\theta_{\tilde{b}} & \left(\mathrm{x}=b_{2}\right) \\
\left(\frac{x-b_{2}+\theta_{\tilde{b}}\left(b_{3}-x\right)}{b_{3}-b_{2}}\right) & \left(b_{2}<x \leq b_{3}\right) \\
1 & \text { otherwise }
\end{array}\right.
\end{gathered}
$$




$$
\mathrm{F}_{\tilde{b}}(x)=\left\{\begin{array}{cc}
\left(\frac{b_{2}-\mathrm{x}+\beta_{\tilde{b}}\left(\mathrm{x}-b_{1}\right)}{b_{2}-b_{1}}\right) & \left(b_{1} \leq x \leq b_{2}\right) \\
\beta_{\tilde{b}} & \left(\mathrm{x}=b_{2}\right) \\
\left(\frac{x-b_{2}+\beta_{\tilde{b}}\left(b_{3}-x\right)}{b_{3}-b_{2}}\right) & \left(b_{2}<x \leq b_{3}\right) \\
1 & \text { otherwise }
\end{array}\right.
$$

Where $\alpha_{\tilde{b}}, \theta_{\tilde{b}}$, and $\beta_{\tilde{b}}$ denote maximum truth membership, minimum indeterminacy membership and minimum falsity membership degrees respectively.

Let $\tilde{b}=\left\langle\left(b_{1}, b_{2}, b_{3}\right) ; \alpha_{\tilde{b}}, \theta_{\tilde{b}}, \beta_{\tilde{b}}\right\rangle$ and $\tilde{c}=\left\langle\left(c_{1}, c_{2}, c_{3}\right) ; \alpha_{\tilde{c}}, \theta_{\tilde{c}}, \beta_{\tilde{c}}\right\rangle$ as two single valued triangular neutrosophic numbers. Addition of two single valued triangular neutrosophic numbers are written as below (Abdel-Basset et al., 2017):

$$
\tilde{b}+\tilde{c}=\left\langle\left(b_{1}+c_{1}, b_{2}+c_{2}, b_{3}+c_{3}\right) ; \alpha_{\tilde{b}} \wedge \alpha_{\tilde{c}}, \theta_{\tilde{b}} \vee \theta_{\tilde{c}}, \beta_{\tilde{b}} \vee \beta_{\tilde{c}}\right\rangle
$$

Subtraction of two single valeued triangular neutrosophic numbers are presented as Eq. (5):

$$
\tilde{b}-\tilde{c}=\left\langle\left(b_{1}-c_{3}, b_{2}-c_{2}, b_{3}-c_{1}\right) ; \alpha_{\tilde{b}} \wedge \alpha_{\tilde{c}}, \theta_{\tilde{b}} \vee \theta_{\tilde{c}}, \beta_{\tilde{b}} \vee \beta_{\tilde{c}}\right\rangle
$$

Inverse of a single valued triangular neutrosophic number $(\tilde{b} \neq 0)$ can be stated as follows:

$$
\tilde{b}^{-1}=\left\langle\left(\frac{1}{b_{3}}, \frac{1}{b_{2}}, \frac{1}{b_{1}}\right) ; \alpha_{\tilde{b}}, \theta_{\tilde{b}}, \beta_{\tilde{b}}\right\rangle
$$

\section{CRITIC (Criteria Importance Through Inter-criteria Correlation) Method}

CRITIC is an objective weighting method proposed by Diakoulaki et al., [19] and rely on two components of information emitted by criteria. Contrast intensity can be defined as the first one seperating each criterion and consider standard deviation as measurement tool.

Conflict between criteria can be handled as second one that is measured by linear correlation coefficient. Steps of CRITIC can be stated as follows [12], [20]:

1- A membership function is desbribed for the purpose of mapping the criteria $K_{i}$ into the interval $[0,1]$ by demonstrating the degree of how alternative $\mathrm{d}$ is close to ideal value of $g_{j}^{*}$ and far from the anti-ideal value of $g_{j}^{-}$. If criteria $\mathrm{j}$ is benefit based $g_{j}^{*}=\max _{i} K_{j}$ and $g_{j}^{-}=\min _{i} K_{j}$, and if $\mathrm{j}$ is cost based $g_{j}^{*}=\min _{i} K_{j}$ and $g_{j}^{-}=\max _{i} K_{j}$. A vector $z_{d j}$ is formed for each criterion and can be written as below:

$$
z_{d j}=\frac{K_{j}-g_{j}^{-}}{g_{j}^{*}-g_{j}^{-}}
$$

2-Standard deviation $\sigma_{j}$ is computed for examining each criterion in terms of each vector $z_{d j}$

3-Symmetric matrix is constructed that shows the linear correlation coefficient $c c_{j j^{\prime}}$.

4-Conflict of criteria can be computed as follows:

$$
\sum_{j=1}^{m}\left(1-c c_{j j^{\prime}}\right)
$$


5-The components of contrast intensity and conflict of criteria are combined as below:

$$
K_{j}=\sigma_{j} \sum_{j=1}^{m}\left(1-c c_{j j^{\prime}}\right)
$$
$10)$ :

6-Normalization process is applied with respect to transmitted value of information as Eq.

$$
w_{j}=\frac{K_{j}}{\sum_{j=1}^{m} K_{j}}
$$

\section{Plithogenic Sets Based CRITIC Method}

In this study plithogenic sets based CRITIC method is applied due to increasing accuracy of examination process under uncertainty. Contradiction degree function as a part of plithogenic set aggregation is considered to achieve more reliable outputs. Steps of the plithogenic sets based CRITIC method can be summarized as below [12].

1-Criteria $K=\left\{K_{1}, K_{2}, \ldots, K_{m}\right\}$, alternatives $A=\left\{A_{1}, A_{2}, \ldots, A_{n}\right\}$ and decision makers $D M=\left\{D M_{1}, D M_{2}, \ldots, D M_{h}\right\}$ are determined.

2-Neutrosophic triangular scale is considered for evaluating criteria by decision makers and shown as Table 2 .

Table 2. Neutrosophic triangular scale
\begin{tabular}{|l|l|l|}
\hline \multicolumn{1}{|c|}{ Importance linguistic variable } & Triangular neutrosophic scale & Rating linguistic variable \\
\hline Very weakly important & $((0.1,0.3,0.35), 0.1,0.2,0.15)$ & Nothing \\
\hline Weakly important & $((0.15,0.25,0.1), 0.6,0.2,0.3)$ & Very low \\
\hline Partially important & $((0.4,0.35,0.5), 0.6,0.1,0.2)$ & Low \\
\hline Equal important & $((0.65,0.6,0.7), 0.8,0.1,0.1)$ & Medium \\
\hline Strong important & $((0.7,0.65,0.8), 0.9,0.2,0.1)$ & High \\
\hline Very strongly important & $((0.9,0.85,0.9), 0.7,0.2,0.2)$ & Very high \\
\hline Absolutely important & $((0.95,0.9,0.95), 0.9,0.1,0.1)$ & Absolute \\
\hline
\end{tabular}

3-Subjective criteria weight's matrix $(\mathrm{V})$ is formed via equations shown as below:

$$
\begin{aligned}
& V=\left[v_{j}^{S}\right]_{1 x m} \\
& v_{j}^{S}=\frac{v_{j h}}{p}
\end{aligned}
$$

where $v_{j}^{s}$ represent the elements of subjective criteria weight's matrix and $v_{h}^{j}$ shows the weight of criteria $K_{j}$ examined by decision maker h.

4-Normalized subjective weight for each criterion is computed as below:

$$
v_{j}^{s n}=\frac{v_{j}^{s}}{\sum_{j=1}^{m} v_{j}^{s}}
$$

5-According to the CRITIC method weight of each criterion is computed by using Eqs. (7)-(10).

6-Plithogenic aggregation operations are applied in order to increase the accuracy of results. For this purpose, normalized subjective weights and objective weights are composed.

Firstly, a contradiction degree cd is determined for each criterion related to the dominant one. Then plithogenic neutrosophic set intersection is described as follows:

$$
\begin{array}{r}
\left(\left(d_{i 1}, d_{i 2}, d_{i 3}\right), 1 \leq i \leq n\right) \wedge p\left(\left(e_{i 1}, e_{i 2}, e_{i 3}\right), 1 \leq i \leq n\right)= \\
\left(\left(d_{i 1} \wedge_{F} e_{i 1}, \frac{1}{2}\left(d_{i 2} \wedge_{F} e_{i 2}\right)+\frac{1}{2}\left(d_{i 2} \vee_{F} e_{i 2}\right), d_{i 3} \vee_{F} e_{i 3}\right)\right), 1 \leq i \leq n
\end{array}
$$




\section{Analysis}

In this study the dimensions of innovation ability for logistics sector are evaluated via plithogenic sets based CRITIC method. For this purpose, dimensions are determined according to the extended literature review made by authors. Then a survey was designed that is suitable for CRITIC method and responded by nine decision makers having experienced in logistic sector. Dimensions of innovation ability for logistics sector can be seen as Table 3 .

Table 3. Dimensions of innovation ability for logistics sector

\begin{tabular}{|l|l|}
\hline Criteria & Dimensions of innovation ability \\
\hline C1 & Learning ability \\
\hline C2 & Research \& development ability \\
\hline C3 & Marketing ability \\
\hline C4 & Production ability \\
\hline C5 & Accessing information resources \\
\hline C6 & Using resources for firm's benefit \\
\hline C7 & Creative thinking ability \\
\hline C8 & Organizational ability \\
\hline C9 & Strategic ability \\
\hline
\end{tabular}

Subjective weights of criteria are calculated according to Eqs. (13), (14) and can be written as Table 4.

Table 4. Subjective weights of criteria

\begin{tabular}{|l|l|}
\hline Criteria & Subjective weights \\
\hline C1 & $((0.88,0.83,0.9), 0.85,0.14,0.12)$ \\
\hline C2 & $((0.93,0.88,0.93), 0.8,0.14,0.14)$ \\
\hline C3 & $((0.8,0.75,0.84), 0.81,0.15,0.13)$ \\
\hline C4 & $((0.69,0.63,0.75), 0.73,0.16,0.16)$ \\
\hline C5 & $((0.89,0.84,0.9), 0.76,0.17,0.16)$ \\
\hline C6 & $((0.8,0.75,0.84), 0.73,0.17,0.17)$ \\
\hline C7 & $((0.92,0.87,0.92), 0.76,0.16,0.16)$ \\
\hline C8 & $((0.85,0.8,0.89), 0.85,0.15,0.12)$ \\
\hline C9 & $((0.89,0.84,0.9), 0.78,0.16,0.15)$ \\
\hline
\end{tabular}

Normalized subjective weights are computed according to Eq. (15) and objective weights are obtained via Eqs. (9)-(12) and stated as Table 5.

Table 5. Normalized subjective weights and objective weights

\begin{tabular}{|l|l|l|}
\hline Criteria & Normalized Subjective weights & Objective weights \\
\hline C1 & $((0.115,0.115,0.114), 0.12,0.1,0.09)$ & $((0.014,0.023,0.025), 0.06,0.112,0.035)$ \\
\hline C2 & $((0.121,0.122,0.118), 0.113,0.1,0.11)$ & $((0.023,0.018,0.0034), 0.021,0.032,0.041)$ \\
\hline C3 & $((0.104,0.104,0.107), 0.114,0.11,0.1)$ & $((0.018,0.022,0.034), 0.018,0.041,0.053)$ \\
\hline C4 & $((0.09,0.087,0.095), 0.103,0.11,0.12)$ & $((0.016,0.035,0.021), 0.046,0.03,0.032)$ \\
\hline C5 & $((0.116,0.117,0.114), 0.107,0.12,0.12)$ & $((0.019,0.037,0.028), 0.012,0.027,0.031)$ \\
\hline C6 & $((0.104,0.104,0.107), 0.103,0.12,0.13)$ & $((0.018,0.026,0.029), 0.03,0.034,0.04)$ \\
\hline C7 & $((0.12,0.121,0.117), 0.107,0.11,0.12)$ & $((0.026,0.028,0.037), 0.031,0.047,0.05)$ \\
\hline C8 & $((0.111,0.111,0.113), 0.12,0.11,0.12)$ & $((0.016,0.017,0.023), 0.021,0.053,0.026)$ \\
\hline C9 & $((0.116,0.117,0.114), 0.11,0.11,0.11)$ & $((0.022,0.013,0.019), 0.032,0.041,0.039)$ \\
\hline
\end{tabular}

Normalized subjective weights and objective weights are combined via plithogenic aggregation operation in terms of contradiction degree according to Eq. (16) and presented in Table 6. 
Table 6. Plithogenic aggregation operation outputs for criteria

\begin{tabular}{|l|l|l|l|}
\hline Criteria & $\begin{array}{l}\text { Contradiction } \\
\text { degree }\end{array}$ & Aggregation & Crisp value \\
\hline C1 & 0 & $((0,0.02,0.052), 0.016,0.038,0.028)$ & 0.0053 \\
\hline C2 & 0.13 & $((0.003,0.023,0.025), 0.017,0.016,0.024)$ & 0.0125 \\
\hline C3 & 0.24 & $((0.061,0.027,0.043), 0.065,0.012,0.005)$ & 0.0014 \\
\hline C4 & 0.34 & $((0.011,0.034,0.018), 0.044,0.008,0.017)$ & 0.0023 \\
\hline C5 & 0.45 & $((0.054,0.036,0.059), 0.032,0.025,0.08)$ & 0.0321 \\
\hline C6 & 0.56 & $((0.047,0.032,0.058), 0.014,0.012,0.062)$ & 0.0251 \\
\hline C7 & 0.68 & $((0.019,0.025,0.034), 0.044,0.056,0.052)$ & 0.0145 \\
\hline C8 & 0.82 & $((0.033,0.052,0.035), 0.019,0.036,0.042)$ & 0.0182 \\
\hline C9 & 0.95 & & 0.0169 \\
\hline
\end{tabular}

According to the Table 6 while C5 (ability of accessing information resources) was obtained as the most important one with having 0.0321 value, C3 (marketing ability) was found as the least important innovation ability criterion for logistics sector. Ranking of other criteria can be written as $\mathrm{C} 6>\mathrm{C} 8>\mathrm{C} 9>\mathrm{C} 7>\mathrm{C} 2>\mathrm{C} 1>\mathrm{C} 4$ respectively.

\section{Conclusion}

In this study dimensions of innovation ability for logistics sector are prioritized via plithogenic sets based CRITIC method. For this purpose, dimensions related to innovatin ability are obtained based on extended literature review process. Plithogenic sets are preferred compared to crisp, fuzzy, intuitionistic, pythagorean and neutrosophic sets due to giving more accurate outputs after the examination process under uncertainty. The criteria were ranked according to the judgments of 9 decision makers having experienced in logistic sector.

Additionally, determining and weighting the innovation ability dimensions for logistics sector can be handled as a real-world decision making problem and appropriate for solving via multi criteria decision making techniques under plithogenic sets. Although the criterion dimensions are close to each other, the C5 criterion (ability of accessing information resources) has made a difference compared to the other dimensions. For future studies dimensions for innovation ability can be expanded and results can be compared with different multi criteria decision making methods. Also, different dimensions can be applied for various logistic based applications.

\section{REFERENCES}

[1] Armbruster, H., Bikfalvi, A., Kinkel, S. \& Lay, G. (2008). Organizational innovation: The challenge of measuring non-technical innovation in large-scale surveys. Technovation, 28, pp. 644-657.

[2] Memiş, S. \& Korucuk, S. (2019). Dematel ve Vikor Bütünleşik Yaklaşımı ile Gıda İşletmelerinde İnovasyon Çeşitlerinin Önceliklendirilmesi ve En İdeal Firma Seçimi, Manas Sosyal Araştırmalar Dergisi, 8(1), pp. 1070-1084.

[3] Erdal, H. (2018). Temel Lojistik İnovasyon Yeteneklerinin Önem Derecelerinin Belirlenmesi: Lojistik Hizmet Sağlayıcılar Üzerine Bir Araştırma. IV. Internatıonal Caucasus-Central Asia Foreign Trade and Logistics Congress September, 7-8, Didim/Aydin.

[4] Çakar, N. D. \& Ertürk, A. (2010). Comparing Innovation Capability of Small and Medium-Sized Enterprises: Examining the Effects of Organizational Culture and Empowerment. Journal of Small Business Management, 48, pp. 325-359.

[5] Forsman, H. (2011). Innovation capacity and innovation development in small enterprises. A comparison between the manufacturing and service sectors. Research Policy, 40(5), pp. 739-750.

[6] Moussaa, N. B. \& El Arbi, R. (2020). The impact of Human Resources Information Systems on individualinnovation capability in Tunisian companies: The moderating role ofaffective commitment. European Research on Management and Business Economics, 26(1), pp. 18-25. 
[7] Hansen, U. E., Larsen, T. H., Bhasin, S., Burgers, R. \& Henrik, L. (2019). Innovation capability building in subsidiaries of multinational companies in emerging economies: insights from the wind turbine industry. Journal of Cleaner Production, 244, pp. 1-12.

[8] Alexe, C.G. \& Alexe, C.M. (2016). The Importance of the Dimensions of the Innovation Management in Evaluating the Innovation Capability of the Firms in the Machine Building Industry in Romania. $9^{\text {th }}$ International Conference Interdisciplinarity in Engineering (pp. 999-1005). Tirgu-Mures, Romania: Procedia Technology.

[9] Khedhaouria, A. \& Thurik, R. (2017). Configurational conditions of national innovation capability: A fuzzy set analysis approach. Technological Forecasting \& Social Change, 120, pp. 48-58.

[10] Nada, N. \& Zulfiqar, A. (2015). Service Value Creation Capability Model to Assess the Service Innovation Capability in SMEs. $7^{\text {th }}$ Industrial Product-Service Systems Conference (pp. 390-395). Procedia CIRP.

[11] Smarandache, F. (2018a). Plithogenic set, an extension of crisp, fuzzy, intuitionistic fuzzy and neutrosophic sets-revisited. Neutrosophic Sets and Systems, 21, pp. 153-166.

[12] Abdel-Basset, M. \& Mohamed, R. (2020). A novel plithogenic TOPSIS-CRITIC model for sustainable supply chain risk management. Journal of Cleaner Production, 247, pp. 1-15.

[13] Cunha, L., Ceryno, P. \& Leiras, A. (2019). Social supply chain risk management: a taxonomy, a framework and a research agenda. Journal of Cleaner Production, 220, pp. 1101-1110.

[14] Smarandache, F. (1998). A unifying field in logics, neutrosophy: neutrosophic probability, set and logic. American Research Press, Rehoboth.

[15] Abdel-Basset, M., Mohamed, M., Zhou, Y.\& Hezam, I. (2017). Multi-criteria group decision making based on neutrosophic analytic hierarchy process. Journal of Intelligent \& Fuzzy Systems, 33, pp. 40554066.

[16] Abdel-Basset, M., Mohamed, M. \& Smarandache, F. (2018). An extension of neutrosophic AHPSWOT analysis for strategic planning and decision making. Symmetry, 10(116), pp. 1-18.

[17] Pamučar, D. \& Božanić, D. (2019). Selection of a location for the development of multimodal logistics center: Application of single-valued neutrosophic MABAC model. Operational Research in Engineering Sciences: Theory and Applications, 2(2), pp. 55-71.

[18] Liu, F., Aiwu, G., Lukovac, V. \& Vukic, M. (2018). A multicriteria model for the selection of the transport service provider: A single valued neutrosophic DEMATEL multicriteria model. Decision Making: Applications in Management and Engineering, 1(2), pp. 121-130.

[19] Diakoulaki, D., Mavrotas, G. \& Papayannakis, L. (1995). Determining objective weights in multiple criteria problems: The critic method. Computers \& Operations Research, 22(7), pp. 763-770.

[20] Puška, A., Stojanović, I. \& Maksimović, A. (2019). Evaluation of sustainable rural tourism potential in Brcko district of Bosnia and Herzegovina using multi-criteria analysis. Operational Research in Engineering Sciences: Theory and Applications, 2(2), pp. 40-54.

[21] Sheng Margaret L., H. N. (2019). Impact of subsidiaries' cross-border knowledge tacitness shared and social capital on MNCs' explorative and exploitative innovation capability. Journal of International Management, 25(4), pp. 1-16.

[22] Smarandache, F. (2018b). Physical plithogenic set. In: APS Meeting Abstracts.

\section{Article history:}

Received 13 April 2020

Accepted 18 May 2020 